\title{
Comment
}

\section{Suicídio: uma análise da última comunicação}

Gemailson Nogueira de Araújo $^{1}$; Gislene Farias de Oliveira ${ }^{2}$

Resumo: Este artigo, discute o suicídio como a ultima escolha do ser humano e, como uma última comunicação, trata de uma análise deste fenômeno no contexto da filosofia e da psicologia na visão de Freud. Mas busca-se, sobretudo, entender os motivos que levam a um individuo a suicidar-se relacionando o suicídio ao processo psicossocial. Assim, diante da hipótese podemos perceber que é um problema atual e pouco estudado na região do Cariri. Trata-se de um estudo bibliográfico como método de interpretação do fenômeno. O objetivo é conhecer a mensagem, na qual o corpo deixa de ser fundamental ao indivíduo. Tanto essa discussão quanto o processo psicossocial humano serão abordados também principalmente, através da visão psicanalítica de Cassorla, 2003.

Palavras-Chave: Suicídio. Comunicação. Psicologia.

\section{Suicide: an analysis of the last communication}

\begin{abstract}
This paper discusses suicide as the last choice of man and, as a last communication, is an analysis of this phenomenon in the context of philosophy and psychology in Freud's view. But seeks, above all, to understand the reasons that lead to an individual to commit suicide suicide relating to the psychosocial process. Thus, on the assumption that we can see it is a current problem and understudied in Cariri. This is a bibliographic study as a phenomenon of the interpretation method. The goal is to know the message, in which the body is no longer important to the individual. Both this discussion as the human psychosocial process will be discussed also especially through the psychoanalytic view of Cassorla 2003.
\end{abstract}

Keywords: Suicide. Communication. Psychology.

\section{Introdução}

Desde os homens mais primitivos, que a humanidade depara com um fenômeno que é inexorável a todo e qualquer ser humano que é: a morte. Como diz Rubem Alves "há uma morte que vem de fora e uma morte que vem de dentro", essa morte que vem de dentro é o que classificamos de Suicídio".

\footnotetext{
${ }^{1}$ Mestrando em Educação pela Anne Sullivan University - Juazeiro do Norte - Ceará - Brasil. E-mail:gemailson@ hotmail.com;

${ }^{2}$ Psicóloga. Doutora em Psicologia Social pela Universidade Federal da Paraíba. Pós doutorado em Ciências da saúde pela Faculdade de Medicina do ABC, São Paulo. Professora da Universidade Regional do Cariri e da Universidade Federal do Cariri - UFCA.

E-mail: gislenefarias@gmail.com.
} 
Id on Line Revista Multidisciplinar e de Psicoloqia

Id on Line Multidisciplinary Journal and Psycology

O impacto da morte não foge ao nosso conhecimento, pois percebemos que as pessoas morrem e temos a consciência de que a vida é uma progressiva sujeição à finitude.

Porém o que significa o suicídio? Seria uma expressão da última escolha humana? Quais as outras possíveis considerações para essa problemática? Albert Camus filósofo francês afirmava: "Só há um problema filosófico serio: o suicídio". O mesmo filosofo também afirmava que "o suicídio é uma conclusão existencial".

Dante Alighieri na sua obra "O Inferno" afirmava que o suicídio é um ato de desespero, talvez um último ato do poder de escolha humana. Uma tentativa de última comunicação que, em vida, não pôde ser compreendida.

$\mathrm{Na}$ verdade, não parece existir uma causa específica para o suicídio. Uma diversidade de fatores assolam o cotidiano do individuo, até se chegar ao último ato. Em geral fatores psicológicos e emocionais. Freud (1975) afirmava que não somos donos da nossa própria casa, que haveria algo de desconhecido dentro do nosso próprio ser. Se pudéssemos fazer uma autópsia psicológica no indivíduo, poderíamos perceber que o suicida não necessarimente quer morrer. A sua real intenção parece ser a de acabar com um sofrimento, que o mesmo percebe como insuportável. Para ele, a única saída possível seria a morte. E com ela o fim do sofrimento.

Em suma, tentar-se-á abordar o assunto através de alguns pontos. O primeiro, uma breve introdução ao suicídio e suas conceituações, bem como as principais discussões filosóficas. Num segundo momento, a visão freudiana, finalisando com a possibilidade da profilaxia à partir da educação.

\section{Conceituação e visão filosófica do suicídio.}

Trata-se de um termo que deriva de dois vocábulos latinos: sui (de si mesmo) e caedĕre (matar), ou seja, matar a si mesmo. Os gregos chamavam o suicídio de morte voluntária. Para outros povos, o suicídio era a consciência de que tudo estaria perdido e, que a vida não valeria mais a pena ser vivida. Uma válvula de escape para a libertação da dor. Os hedonistas incentivavam seus alunos ao suicídio, numa aparente vã tentativa de encontrar o prazer, pela libertação da dor, através da morte voluntária. 
O suicídio nem sempre foi estigmatizado. Grandes filósofos do passado o consideravam uma saída perfeitamente aceitável para circunstâncias insuportáveis. Sêneca dizia ser uma espécie de vantagem dos homens sobre os demais animais. A possibilidade de, metaforicamente, ir-se embora da vida. O filosofo Romeno Cioran, abordou o tema como solidão, isto é, o individuo suicida seria um solitário em seu mundo solipsista. Cioran afirmava que, o despertar em meio à noite, quando buscamos desesperadamente por uma derradeira explicação ante nossas dificuldades, e constatamos a nossa solidão, pois todos dormem, podese pensar em abandonar o mundo, ante a percepção de não ser possível a visa sozinho.

O tema somente daria nova reviravolta na idade média. Por essa época o suicídio começa a ser pensado como uma afronta a Deus. Daí, passa-se a ser execrado pela sociedade. Nesse período, os suicidas não eram tidos como dignos de serem sepultados. Para a Igreja Católica, equivaleria a um pecado mortal, a saber,

\begin{abstract}
Na Idade Média, o suicídio é rechaçado, implacavelmente, sem nenhum tipo de incerteza. O suicídio era um pecado imperdoável. Matar-se era uma afronta a Deus, que deu o sopro de vida, o animus, à materialidade humana. Daí Santo Tomás de Aquino afirmar que "suicídio é sempre pecado mortal, porque vai contra à caridade e à lei natural". Dante, por seu turno, condena ao fogo do inferno todos os suicidas. Lá, no segundo giro do sétimo Circulo do Inferno, estão as almas fadadas ao terrível castigo por causa da prática mortal. (PUENTE, Fernando Rey (Org.) Os filósofos e o suicídio. Belo Horizonte: UFMG, 2008, p.32)
\end{abstract}

Albert Camus comparou a vida, ao Mito de Sísifo, no qual o individuo seria obrigado pelos deuses a, diariamente, levar uma pedra ate o fim do dia, subindo um morro. Na chegada em cima, a pedra deveria tombar, para que novamente se pudesse fazer o mesmo percurso de volta. Nesse sentido Camus comparou a enfadonha monotonia do dia a dia, com a falta de sentido desta, para o suicida.

Segundo a mitologia, o herói Sísifo foi condenado pelos deuses a realizar um trabalho inútil e sem esperança de vida. Sua penitência era empurrar sem descanso, uma enorme pedra até o alto de uma montanha. De onde ele deveria deixa-a rolar encosta abaixo. Esse herói mitológico deveria então descer para em seguida, a empurrar novamente, até o alto do rochedo. E assim, indefinidamente, numa repetição monótona e interminável através dos tempos. 
Os deuses tinham condenado Sísifo a rolar um rochedo incessantemente até o cimo de uma montanha, de onde a pedra caía de novo por seu próprio peso. Eles tinham pensado, com as suas razões, que não existe punição mais terrível do que o trabalho inútil e sem esperança. CAMUS, 1942, p.161).

O mito de Sísifo traz a tona uma problemática essencial da filosofia. A questão do sentido da vida. Aqui marcado pela monotonia e, pcoisificação existencial da mesma. Para Camus, uma saída possível seria o suicídio. Diante do suicídio estaria, a ilusão da liberdade. Diante do conflito, a opção pela liberdade, isto é, livrar-se da vida marcada pela irracionalidade.

\section{Visão de Freud acerca do suicídio}

Freud como fundador da psicanálise, descobre algo que revoluciona o pensamento humano que é o inconsciente. Parte desconhecida da mente consciente, muitas das vezes guardando parte da realidade cotidiana humana. Não há em sua obra, algo que fale diretamente sobre o suicídio. Porém em seu texto sobre "uma psicogênese de um caso de homossexualidade feminina", o autor discute o tema com bastante singularidade, relatando que o suicídio da jovem, no texto, não fora um ato autopunitivo, mas, uma forma de realizar um desejo inconsciente.

\footnotetext{
O desejo inconsciente referia-se ao seu objetivo de conseguir um filho com o pai, e este era um dos motivos pelos quais a moça optara pela homossexualidade, pois em sua fantasia isso a preservaria do risco de manter relações com seu progenitor... O aspecto autopunitivo relacionava-se ao desejo de morte que nutria contra o pai por não consentir que havia tido com o seu progenitor o filho que ela mesma desejava ter conseguido dele. (FARIA, 1997, pp. 29-30).
}

A partir dessa obra poderemos pensar o suicídio, não apenas como uma rejeição a solidão como fora antes explicitado, mas como uma nova concepção: o suicídio de não querer matar só a si própria, mais matar outra pessoa, deixando-lhes com a culpa

Freud analisa a questão da fantasia a um nível inconsciente, tentando abstrair a mentalidade dos suicidas. Aparecem alguns relatos de encontros com pessoas queridas que já partiram. O suicida buscaria a paz interior, ao tentar encontrar-se com alguém que já morreu. 
Outro aspecto que chama a atenção, nos casos de suicídio, é o tom agressivo nos relatos dos suicidas, através das cartas deixadas pelos mesmos. Nestes casos, não há espaço para a defesa de quem foi citado em tais relatos. A culpa ficaria para toda a vida.

Pensando no suicídio autoagressivo em alguns deprimidos, nos quais, por detrás dessa sua autodestruição fatal, desvelava-se um desejo forte em matar alguém, assim, parafraseando o criador da psicanálise, poder-se-ia dizer que é exclusivamente esse sadismo que soluciona o enigma da tendência ao suicídio, tornando a melancolia tão intensa e perigosa, pois "ninguém mata a si próprio, sem antes querer matar um outro (FREUD, 1917/1989).

Enfim, quando observa-se o suicídio nos escritos psicanalíticos, além dessas explanações sobre Freud, nota-se muitos outros autores pós-freudianos, debatendo sobre essa problemática. Porém não é nossa intenção esgotar o estudo mas sim, abrir espaço para outras discussões.

\section{Profilaxia através da Psicologia}

O contexto do meio em que se vive, exerce grande influência na construção do individuo. Portanto, a educação pode vir a ser uma forte aliada ante os anseios humanos.

Não se trata de transformar a sala de aula em um divã. Mas é tarefa do educador, a seleção de ferramentas para compteender melhor as necessidades e frustrações do aluno, com vistas a ajuda-lo no seu processo de enfrentamento dos seus dilemas e angústias.

Seriam essas tão letais ao indivíduo? Quais os motivos que tenderiam a levar alguém a prática do suicídio?

Para Lacan a angústia seria um desses motivos.

A angústia, segundo Lacan, é o único afeto que não engana, visto que é real e experimentado no corpo. O sujeito deprimido é aquele mergulhado numa angústia desmedida, angústia materializada no corpo sob a forma de dor. Dói o corpo, dói o peito, dói a alma, como relatam alguns pacientes. É comum atribuírem a esta dor a causa precipitante do seu ato suicida, quando afirmam que matar-se seria a única forma de livrar-se dela ( CFP:2013) 
São questões como essas que se depara muitas vezes o psicólogo. Nem sempre de fácil solução. Como ajudar alguém que se apresenta com o desejo de morrer? Um sujeito que só encontra a angústia e que, a nível inconsciente, pode estar buscando encontrar alguém e/ou uma satisfação, em algum lugar "do outro lado da vida".

E assim, seja como analista, seja como psicólogo, o profissional não deve recuar diante da morte, devendo estar advertido de que, para além do sofrimento do qual o sujeito se lamenta, há uma satisfação, um gozo, mortífero sem dúvida, mas há gozo, o gozo da morte. E se um sujeito escolhe a morte, ele o faz não porque a deseja, visto que o inconsciente não a reconhece, mas porque dela pretende obter alguma satisfação (CFP: 2013)

Segundo a Organização Mundial de Saúde, os principais motivos que levam uma pessoa a cometer suicídio, estariam relacionados com: depressão, raiva, sentimento de culpa, sentimento de perda, problemas familiares e financeiros e não saber lidar com as frustações. Em resumo, é necessário um aprofundamento muito maior sobre essa temática, de forma a se promover uma real contribuição acerca dos motivos dos suicidas, para que subsidiar programas de saúde pública, capazes de prevenir tais atentados contra a vida humana.

\section{Considerações Finais}

Com base nas leituras dos atores citados, pôde-se constatar neste estudo, que os indivíduos que cometem suicídio, apresentam menor flexibilidade para resolução de problemas e, maiores níveis de desesperança. Tais situações não são definidoras em si, da decisão suicida, mas implicam no fato do indivíduo não sentir-se forte para lutar e agir, quando não vê saídas para seus problemas. Como afirma o Conselho Federal de Psicologia, co relação ao comportamento suicida, "verifica-se associação significativa entre desesperança e deficiência, e ainda uma menor flexibilidade na resolução de problemas".

Sabe-se que o corpo fala, seja ele vivo ou morto. O que se compreende no cadáver de um suicida é que o corpo parece ser sua última forma de comunicar suas necessidades e sofrimento. 
Id on Line Revista Multidisciplinar e de Psicoloqia

Id on Line Multidisciplinary Journal and Psycology

Seja o desejo de culpar alguém ou simplesmente deixar uma mensagem que será ecoada por toda a eternidade, o suicídio é um fenômeno paradoxal. De acordo com o Conselho Federal de Psicologia - CFP, "de um lado aparece como a mais pessoal das ações que um indivíduo pode cometer. De outro, ocorre ao longo da história humana". Em todos os cantos do mundo há relatos de tais procedimentos, onde os fatores sociais parecem desempenhar um papel importante, senão decisivo em tal escolha (DIEKSTRA et al., 1989, p. 23).

\section{Referências}

CAMUS, Albert. $O$ Mito de Sísifo: ensaio sobre o absurdo. Tradução por Urbano Tavares Rodrigues e Ana de Freitas. [Lisboa]: Edição Livros do Brasil, 1942. 244 p. Título original: Le Mythe de Sisyphe.

CASSORLA, R. Jovens que tentam o suicídio. Tese de Doutorado, Universidade Estadual de Campinas, Campinas, SP, 1981.

O que é o suicídio. São Paulo: Brasiliense. 1984.

CONSELHO FEDERAL DE PSICOLOGIA - CFP. O Suicídio e os Desafios para a Psicologia / Conselho Federal de Psicologia. - Brasília: CFP, 2013.

FARIA, F. M. A questão do suicídio na clínica. Uma leitura Winnicottiana. Dissertação de Mestrado, Pontifícia Universidade Católica de São Paulo. São Paulo, 1997.

FREUD, S. Sobre la psicogénesis de un caso de homosexualidad femenina. In S. . Obras completas(Vol. 18). Buenos Aires: Amorrortu, 1975. (Trabalho original publicado em 1920)

PUENTE, Fernando Rey (Org.) Os filósofos e o suicídio. Belo Horizonte: UFMG, 2008

\section{Como citar este artigo (Formato ABNT):}

ARAÚJO, G.N.; OLIVEIRA, G.F. Suicídio: uma análise da última comunicação. Id on Line Revista Multidisciplinar e de Psicologia, Set-Out/2016, vol.10, n.31, Supl 1. p. 248-254. ISSN 1981-1179.

Recebido: 20/08/2016.

Aceito: 23/08/2016 